\title{
MiR-4448 is involved in deltamethrin resistance by targeting CYP4H31 in Culex pipiens pallens
}

Xixi Li ${ }^{\dagger}$, Shengli Hư ${ }^{\dagger}$, Haitao Yin, Hongbo Zhang, Dan Zhou, Yan Sun, Lei Ma, Bo Shen ${ }^{*}$ and Changliang Zhu

\begin{abstract}
Background: Culex pipiens (Cx. pipiens) complex, which acts as a vector of viruses and is widespread and abundant worldwide, including West Nile virus, Japanese encephalitis virus, and Sindbis virus, can cause serious vector-borne diseases affecting human health. Unfortunately, mosquitoes have developed deltamethrin resistance because of its long-term overuse, representing a major challenge to mosquito control. Understanding the molecular regulatory mechanisms of resistance is vital to control mosquitoes. MicroRNAs (miRNAs) are short non-coding RNAs that have been demonstrated to be important regulators of gene expression across a wide variety of organisms, which might function in mosquito deltamethrin resistance. In the present study, we aimed to investigate the regulatory functions of miR-4448 and CYP4H31 in the formation of insecticidal resistance in mosquito Culex pipiens pallens.
\end{abstract}

Methods: We used quantitative real-time reverse transcription PCR to measure miR-4448 and CYP4H31 (encoding a cytochrome P450) expression levels. The regulatory functions of miR-4448 and CYP4H31 were assessed using dualluciferase reporter assays. Then, oral feeding, RNA interference, and the American Centers for Disease Control and Prevention bottle bioassay were used to determine miR-4448's association with deltamethrin resistance by targeting CYP4H31 in vivo. Cell Counting Kit-8 (CCK-8) was also used to detect the viability of plB/N5-His-CYP4H31-transfected C6/36 cells after deltamethrin treatment in vitro.

Results: MiR-4448 was downregulated in the deltamethrin-resistant strain (DR strain), whereas CYP4H31 was downregulated in deltamethrin-susceptible strain. CYP4H31 expression was downregulated by miR-4448 recognizing and binding to its $3^{\prime}$ untranslated region. Functional verification experiments showed that miR-4448 overexpression resulted in lower expression of CYP4H31. The mortality of miR-4448 mimic-injected DR strain mosquitoes was higher than that of the controls. CCK-8 assays showed that CYP4H31 decreased cellular resistance to deltamethrin in vitro and the mortality of the DR strain increased when CYP4H31 was knocked down in vivo.

Conclusions: In mosquitoes, miR-4448 participates in deltamethrin resistance by targeting CYP4H31. The results of the present study increase our understanding of deltamethrin resistance mechanisms.

Keywords: MicroRNA, Cytochrome P450, Insecticide resistance, CDC bottle, Mosquito

*Correspondence: shenbo@njmu.edu.cn

${ }^{\dagger}$ Co-authors: Xixi Li and Shengli Hu contributed equally to this work Department of Pathogen Biology, Nanjing Medical University, Nanjing, Jiangsu 211166, People's Republic of China

\section{Background}

Many serious neglected tropical diseases (NTDs) diseases, including Zika, yellow fever, dengue fever, West Nile fever, and malaria, are transmitted by mosquitoes [1-4]. Globalization and international travel have contributed to transnational pathogen and vector dispersion,

(C) The Author(s) 2021. This article is licensed under a Creative Commons Attribution 4.0 International License, which permits use, sharing, adaptation, distribution and reproduction in any medium or format, as long as you give appropriate credit to the original author(s) and the source, provide a link to the Creative Commons licence, and indicate if changes were made. The images or other third party material in this article are included in the article's Creative Commons licence, unless indicated otherwise in a credit line to the material. If material is not included in the article's Creative Commons licence and your intended use is not permitted by statutory regulation or exceeds the permitted use, you will need to obtain permission directly from the copyright holder. To view a copy of this licence, visit http://creativeco mmons.org/licenses/by/4.0/. The Creative Commons Public Domain Dedication waiver (http://creativecommons.org/publicdomain/ zero/1.0/) applies to the data made available in this article, unless otherwise stated in a credit line to the data. 
representing a key threat for millions of people and animals worldwide $[5,6]$. Among these vectors, Culex pipiens complex is widely distributed worldwide and plays important roles in the transmission of many human diseases [7]. Over the past 2 decades, insecticide-based approaches to control mosquito vectors have substantially reduced the prevalence of mosquito borne diseases, including malaria [8]. Deltamethrin is a pyrethroid insecticide that is commonly used and recommended for inhome insect control because of its high efficiency, broad spectrum, and relatively low toxicity to humans $[9,10]$. Unfortunately, mosquito resistance to insecticides has developed because of their long-term heavy use [11].

Studies showed that the development of insecticide resistance in mosquitoes is a complex and heritable evolutionary phenomenon, involving multiple genes and mechanisms [12]. Improving our understanding of the molecular mechanisms of insecticide resistance would allow the formulation of novel strategies to minimize and prevent resistance development, thus controlling mosquitoes [13]. To date, research has largely focused on identifying insecticide resistance-related genes and has found that the evolution of insecticide resistance is mostly induced by changes in the expression of cytochrome P450 genes [14]. In resistant mosquitoes, several P450 genes are upregulated and overexpressed [15-17]. However, the regulatory mechanisms of P450s remain largely unknown.

MicroRNAs (miRNAs) are a class of evolutionarily highly conserved non-coding small RNAs. They are 21-22 nucleotides in size and are widely distributed in eukaryotic cells [18]. MiRNAs negatively regulate gene expression at the mRNA level by recognizing and binding to $3^{\prime}$ untranslated regions (UTRs) [19]. They could lead to degradation of the target mRNA or inhibition of its translation, resulting in decreased production of the protein [20]. Similar to those in other animals and insects, mosquito miRNAs (22-24 nt) degrade their target mRNAs to regulate the host-pathogen interactions, metabolism, development, and insecticide resistance; however, miRNAs' precise role in deltamethrin resistance remains mostly unknown [21].

The present study aimed to use previously identified differentially expressed miRNAs between a deltamethrin-resistant (DR-) strain and a deltamethrin-susceptible (DS-) strain of Culex pipiens pallens [22] to investigate miRNAs related to mosquito deltamethrin resistance. Quantitative real-time reverse transcription PCR (qRT-PCR) was used to verify the expression level of miR-4448 in DS and DR strain mosquitoes. Bioinformatic predictions and dual-luciferase assays were used to identify the potential target of miR-4448. Next, RNA interference (RNAi) was performed for miR-4448 and its target CYP4H31 using oral feeding or microinjection, and then the mortality of mosquitoes was detected using CDC bottle bioassays in vivo. Cell Counting Kit-8 (CCK8 ) was also applied to verify the viability of $\mathrm{C6} / 36$ cells transfected with CYP4H31 in vitro. These experiments helped us to determine whether miR-4448 is involved in deltamethrin resistance by targeting CYP4H31 in Culex pipiens pallens.

\section{Materials and methods}

Insects

In this study, we used two strains of Culex pipiens pallens with different resistance levels to deltamethrin mosquitoes. The DS strain of Culex pipiens pallens used in the present study was obtained from Ji Nan University and maintained in the laboratory with a constant light/dark cycle $(14: 10 \mathrm{~h})$ at $28{ }^{\circ} \mathrm{C}$ and $70-80 \%$ relative humidity. Adults were provided with $5 \%(\mathrm{w} / \mathrm{v})$ sterilized sugar [glucose (5 g, GHTECH, Guangdong, China) was dissolved in $100 \mathrm{ml}$ of deionized water and autoclaved] on a Scotch-Brite ${ }^{\mathrm{TM}}$ sponge wick (3 M, Shanghai, China) ad libitum. Mosquitoes were fed on mouse blood to reproduce the next generation. The DR strain was selected from the DS strain and was maintained via treatment with deltamethrin at the $50 \%$ lethal concentration $\left(\mathrm{LC}_{50}\right)$ of each generation $\left(G_{\mathrm{n}}\right)$. There were 4000 larvae for screening in each pool (three pools $/ G_{\mathrm{n}}$ ). For the DS and DR strains, the $\mathrm{LC}_{50}$ values were 0.04 and $8.5 \mathrm{mg} / \mathrm{l}$, respectively. Deltamethrin (technical, 99.0\%) was a gift from Jiangsu Provincial Center for Disease Control and Prevention (Jiangsu, China). Procedures for blood-feeding with mice in our laboratory were monitored by The National Science and Technology of China and People's Government of Jiangsu Province Animal Care and Use Committee and Institutional Review Board (no. IACUC-1812047).

\section{Genomic DNA extraction, pre-miR-4448 amplification, and cloning}

Genomic DNA (gDNA) was extracted from 3-day post-eclosion ( $3 \mathrm{~d}$ PE) female adult mosquitoes $(N=1)$ using a MiniBEST Universal Genomic DNA Extraction Kit, version 5.0 (Takara, Dalian, China), following the manufacturer's instructions. gDNA quantity and quality were checked using a Thermo Scientific ${ }^{\mathrm{TM}}$ NanoDrop 2000 instrument (Thermo Fisher Scientific, Waltham, MA, USA).

Using the gDNA as a template, PCR was performed using primers (Table 1) designed according the $C x$. pipiens pallens pre-miRNA sequence with the following conditions: $94^{\circ} \mathrm{C}$ for $5 \mathrm{~min}$; followed by 35 cycles of $94{ }^{\circ} \mathrm{C}$ for $30 \mathrm{~s}, 56{ }^{\circ} \mathrm{C}$ for $30 \mathrm{~s}$, and $72{ }^{\circ} \mathrm{C}$ for $10 \mathrm{~s}$; and a 
final extension step at $72{ }^{\circ} \mathrm{C}$ for $10 \mathrm{~min}$. The PCR products were subjected to electrophoresis through a $2.0 \%$ agarose gel. A PCR fragment of around 80 bp was isolated from the gel and purified using a MiniBEST Agarose Gel DNA Extraction Kit version 4.0 (Takara) and then cloned into vector PMD 19-T (Takara). Ten microliters of the resultant plasmid was transferred into $100 \mu \mathrm{l}$ of Escherichia coli One Shot ${ }^{\circledR}$ TOP10 Competent Cells (Invitrogen, Carlsbad, CA, USA) for amplification [23]. Colonies were selected and analyzed using PCR and sequencing.

\section{Identifying the miR-4448 precursor and the potential target of miR-4448}

First, the miR-4448 precursor (pre-miR-4448) sequence was identified to ensure that the miRNA actually existed in $C x$. pipiens pallens rather than being a sequencing artifact. We obtained a 90-bp pre-miR-4448 nucleotide sequence (GCTCGCACCACAACCCCGAATCACCGC GAG CGTACCGCC ACTCCAGCACTCATG GCAC GGCTCGATGGTCTAGGGGTATGATTCTCGCTT) by sequencing. The miR-4448 sequence is shown in bold. To identify the putative gene targets of miR-4448, we used $3^{\prime}$ UTR sequences from the $C x$. quinquefasciatus genome in the RNAhybrid target prediction program [24]. We focused on the CYP family genes that participate in the regulation insecticidal resistance of mosquitoes, and only CYP4H31 was identified as a potential target of miR-4448. To assess the conservation of the $3^{\prime}$ UTR, we amplified the $3^{\prime}$ UTR from $C x$. pipiens pallens. The $3^{\prime}$ UTR sequence of CYP4H31 in Cx. pipiens pallens was $100 \%$ identical with that from $C x$. quinquefasciatus. Then, qRT-PCR was used to detect the expression levels of miR-4448 and CYP4H31 in the DS and DR strains.

\section{Quantitative real-time reverse transcription PCR (qRT-PCR)} analyses

At $3 \mathrm{~d}$ PE, DS and DR strain female adult mosquitoes $(N=10)$ were subjected to total RNA extraction using the RNAiso Plus reagent (Takara). The total RNA purity and concentration were checked using a NanoDrop spectrophotometer. The cDNA was synthesized from $1 \mu \mathrm{g}$ of total RNA using a PrimeScript RT reagent Kit (Takara) and PrimeScript ${ }^{\mathrm{TM}}$ RT Master Mix (Takara) according to the manufacturer's protocol. The cDNA was diluted $1: 10$, and $4 \mu \mathrm{l}$ of the diluted cDNA solution was used as template for quantitative real-time PCR (qPCR) using the Power SYBR Green PCR Master Mix (Applied Biosystems, Foster City, CA, USA). PCR was performed in a $20-\mu \mathrm{l}$ reaction mix containing $10 \mathrm{pmol}$ of forward and reverse PCR primers [designed using Primer Premier 6.0 software (PREMIER Biosoft International, San Francisco, CA, USA)] for miR-4448 and CYP4H31 (Table 1). MiR4448 expression was measured using the Stem-loop RTPCR method [25] with the following reaction conditions: $50{ }^{\circ} \mathrm{C}$ for $2 \mathrm{~min}$ and $95^{\circ} \mathrm{C}$ for $10 \mathrm{~min} ; 40$ cycles of $95{ }^{\circ} \mathrm{C}$ for $15 \mathrm{~s}$ and $60{ }^{\circ} \mathrm{C}$ for $1 \mathrm{~min}$, followed by melting-curve analysis on an ABI Prism 7300 real-time PCR Instrument (Applied Biosystems). The relative expression level of miR-4448 was normalized to the internal control U6 small nuclear (U6), and the CYP4H31 expression level was normalized to that of $\beta$-actin from the DS and DR strains. The DS strain expression level was designated as 1. For each experiment, RNA from three biological replicates was used, and PCR amplification of each cDNA sample was performed in triplicate. The $2^{-\Delta \Delta \mathrm{Ct}}$ method was used to calculate the relative expression levels [26].

\section{PMIR-REPORT vector construction, cell culture, and dual-luciferase reporter assay}

We identified the region of the CYP4H31 $3^{\prime}$ UTR that included the complementary sequences predicted to bind miR-4448. To mutate this region, the binding site

Table 1 Oligonucleotide sequences of miR-4448, U6, CYP4H31, and $\beta$-actin used for PCR and vector constructs in the present study

\begin{tabular}{lll}
\hline Name & Forward $\left(5^{\prime}-3^{\prime}\right)$ & Reverse $\left(5^{\prime}-3^{\prime}\right)$ \\
\hline pre-miR-4448 & GCTCGCACCACAACCCCG & AAGCGAGAATCATACCCCTAGACCA \\
miR-4448 (RT-stem ring) & CTCAACTGGTGTCGTGAGTCGGCAATTCAGTTGAGCATACCCC \\
miR-4448 & ACACTCCAGCTGGGGGTCGATGGTCTAGG \\
U6 & GCTTCGGCTGGACATATACTAAAAT & TGGTGTCGTGGAGTCG \\
CYP4H31 & ACTTTGATGGCGTTGGATAGC & GAACGCTTCACGATTTTGCG \\
B-actin & AGCGTGAACTGACGGCTCTTG & AATCCCGCAAGAGGACTGAC \\
CYP4H31 3' UTR-WT & CGAGCTCAAACCTGTTGATATTTTACTGGCA & ACTCGTCGTACTCCTGCTTGG \\
CYP4H31 3' UTR- $\triangle$ & CGAGCTCAAACCTGTTGATATTTTACTGGCA & CCAAGCTTTTTTTGCGCTCGATGGTTT \\
plB/N5-His-CYP4H31 & GGACTAGTGAGATGGAAATGCTGATTGAGATCGTACTGG & CCAAGCTTTTTTTGCCCACCAAGGTTT \\
\hline
\end{tabular}


complementary region (AUCGAGC) was replaced by UUGGUGG ( $3^{\prime}$ UTR- $\Delta$ ). Two pairs of primers were designed according to the transcript sequences from $C x$. quinquefasciatus to amplify the wild-type (WT) $3^{\prime}$ UTR and $3^{\prime}$ UTR- $\triangle$ of CYP4H31 (Table 1). Luciferase constructs were made by amplifying and sequencing the $C x$. quinquefasciatus putative target $3^{\prime}$ UTR-WT/3' UTR- $\Delta$ sequence of the CYP4H31 mRNA (containing the putative seed region of the miR-4448 binding sites) and using the T/A cloning method to insert them into the HindIII and XbaI sites located downstream of the Renilla translational stop codon within the pMIR-REPORT miRNA Expression Reporter Vector (Promega, Madison, WI, USA) [17].

At $48 \mathrm{~h}$ after transfection of the pMIR-REPORT constructs, assays were performed using the dual-luciferase reporter assay system (Promega). 293T cells were cultured in Dulbecco's modified Eagle's medium (DMEM; Gibco, Grand Island, NY, USA) supplemented with $10 \%(\mathrm{v} / \mathrm{v})$ fetal calf serum (FCS; Gibco) in a $5 \%$ $\mathrm{CO}_{2}$-humidified incubator at $37{ }^{\circ} \mathrm{C}$ [18]. Then, $6 \times 10^{4}$ cells/well in $2.5 \mathrm{ml}$ of complete growth medium was seeded and incubated in a 6-well plate for $24 \mathrm{~h}$ until they reached $>80 \%$ confluency. Then, $6 \mathrm{ng}$ of pMIRREPORT-UTR-WT or pMIR-REPORT- UTR- $\Delta$ treated with $6 \mu$ lof miR-4448 mimic and miRNA negative control (NC1) (GenePharma, Shanghai, China) along with 6 ng of PGL4.7 (Promega) was cotransfected using the FuGENE HD transfection reagent (Promega). Vector PGL4.7, which constitutively expresses Renilla luciferase, was cotransfected as an internal control to correct for differences in the efficiency of transfection and harvest between the groups. In each sample, Renilla luciferase was normalized using Firefly luciferase expression [19]. An M200 microplate fluorescence reader (Tecan, Lyon, France) was used to detect the luciferase activity. Cells were treated in triplicate, and the transfections were repeated three times.

\section{Oral feeding}

For the oral feeding experiments, all the materials (e.g. water, glucose, and sponges) were treated with diethyl pyrocarbonate (DEPC; Sangon Biotech, Shanghai, China) to remove RNase. In each cage, DR strain pupae $(N=120)$ of $C x$. pipiens pallens were collected in a plastic cup. The post-eclosion (PE) mosquitoes were starved for $12 \mathrm{~h}$. The 12-h PE adults of the blank group (WT) were treated with $5 \%$ glucose water, while the negative control group (NC1) was given the miRNA mimic control dissolved in $5 \%$ glucose water, at a final dose of $100 \mathrm{nmol} / \mathrm{l}$. The experimental group (miR-4448 mimic) was parallelly supplied with the miR-4448 mimic $(100 \mathrm{nmol} / \mathrm{l})$. At $48 \mathrm{~h}$ after treatment, RNA was extracted from female adult mosquitoes to validate the expression of miR-4448 and its target gene CYP4H31. The miR-4448 mimic and miRNA control mimic were obtained from GenePharma (Table 2).

\section{Microinjection of miR-4448 mimic and CYP4H31 siRNA (si-CYP4H31)}

Microinjections were conducted using a Nanoject III aspirator tube assembly (cat. no. 3-000-207, Drummond Scientific Co., Broomall, PA, USA) fitted with a needle puller (Sutter P-97, Sutter Instrument, Novato, CA, USA) and a glass capillary needle (3.5", Drummond). GenePharma designed and synthesized a small interfering RNA targeting the open reading frame (ORF) of CYP4H31 (siCYP4H31) (Table 2). For the microinjection of miRNA, DR strain female adult mosquitoes were collected within $12 \mathrm{~h} \mathrm{PE}$ and frozen at $-20^{\circ} \mathrm{C}$ for $3-5 \mathrm{~min}$. These mosquitoes were divided into three groups and injected in the thorax with different moieties. The negative control group ( $\mathrm{NC1}$ ) was injected with $0.5 \mu \mathrm{l}$ of miRNA control mimic at a dose of $20 \mathrm{nmol} / \mathrm{l}$, and the experimental group (miR-4448 mimic) was injected with $0.5 \mu \mathrm{l}$ of the miR-4448 mimic under the same conditions at a final dose of $20 \mathrm{nmol} / \mathrm{l}$. For the microinjection of siRNA, the negative control group (NC2) was injected with $69 \mathrm{nl}$ of control at a dose of $5 \mu \mathrm{g} / \mu \mathrm{l}$, and the experiment group (siCYP4H31) was injected with $69 \mathrm{nl}$ of si-CYP4H31 under the same conditions at a final dose of $5 \mu \mathrm{g} / \mu \mathrm{l}$. Thereafter, the mosquitoes were transferred to holding tubes and maintained in our laboratory with a constant light/dark cycle $(14: 10 \mathrm{~h})$ at $28{ }^{\circ} \mathrm{C}$ with $70-80 \%$ humidity. After $72 \mathrm{~h}$, the expression levels of miR-4448 and its target gene CYP4H31 were validated using qRT-PCR. Three biological replicates with three technical replicates, each replicate containing 20 female mosquitoes, were performed.

\section{Eukaryotic expression vector pIB/V5-His construction, cell culture, and transfection}

Standard molecular biology procedures were used for plasmid construction [27]. Overlap PCR was performed to amplify the ORF of CYP4H31 using corresponding primer pairs (Table 1) from $C x$. quinquefasciatus, which was inserted between unique restriction enzyme sites (SpeI/Xhol) of the eukaryotic expression vector, pIB/ V5-His (Invitrogen). The positive recombinant plasmid, named pIB/V5-His-CYP4H31, was confirmed using DNA sequencing.

Aedes albopictus C6/36 cells (CRL-1660; ATCC, Manassas, VA, USA) were cultured in DMEM supplemented with $10 \%(\mathrm{v} / \mathrm{v})$ FCS. The $\mathrm{C} 6 / 36$ cells were grown in a 6-well plate at $28{ }^{\circ} \mathrm{C}$ in a $5 \% \mathrm{CO}_{2}$-humidified incubator at. The cells were then plated at $5 \times 10^{5}$ cells/well and 
incubated for $24 \mathrm{~h}$ in a 6-well plate in $2.5 \mathrm{ml}$ of complete growth medium. The cells were transfected when they reached $60-80 \%$ confluence. The transfection protocol was as follows: the plasmid DNA (pIB/V5-His-CYP4H31) was diluted to $1.5 \mathrm{ng}$ per $100 \mu \mathrm{l}$ in complete growth medium followed by the addition of $5 \mu \mathrm{l}$ of FuGENE HD transfection reagent. The DNA mixture was incubated at room temperature for $25 \mathrm{~min}$ and then added to the medium below the surface. The plate was rocked back and forth and from side to side to ensure distribution over the entire plate surface. Meanwhile, C6/36 cells transfected with $\mathrm{pIB} / \mathrm{V} 5$-His were used as controls. Three biological replicates with three technical replicates were performed.

\section{qRT-PCR and Western blotting analysis of CYP4H31 in the transfection cells}

At $48 \mathrm{~h}$ after transfection, the transiently transfected C6/36 cells were subjected to western blotting and qRTPCR. To evaluate the CYP4H31 transfection efficiency, total RNA was isolated from the transfected cells, and qRT-PCR was performed, as described above, to check the expression level of $C Y P 4 H 31$.

Transfected cells were washed with phosphate-buffered saline (PBS). Protein was extracted from the cells after digestion with trypsin solution and lysis using radioimmunoprecipitation assay (RIPA) buffer (Beyotime, Shanghai, China). Protein concentrations were tested using a bicinchoninic acid (BCA) Protein Assay kit (Pierce, Rockford, IL, USA). Soluble protein $(50 \mu \mathrm{g})$ was denatured and subjected to $10 \%$ SDS-PAGE. Proteins were transferred to a nitrocellulose membrane using Trans-Blot SD Cell and Systems for $60 \mathrm{~min}$ at $300 \mathrm{~mA}$ (Bio-Rad, Hercules, CA, USA). The membrane was washed twice in $1 \times$ Trisbuffered saline-Tween 20 (TBS-T), and then blocked for $60 \mathrm{~min}$ at $37^{\circ} \mathrm{C}$ in $5 \%$ Difco ${ }^{\mathrm{TM}}$ Skim Milk (BD Biosciences, San Jose, CA, USA). The membrane was incubated with anti-His-Tag monoclonal primary antibodies (1:1000, NovaGen, Madison, WI, USA) and $\beta$-actin monoclonal primary antibodies (1:2000, ABGENT, Suzhou, China), with shaking overnight at $4{ }^{\circ} \mathrm{C}$. The membranes were then washed with TBS-T and incubated with horseradish peroxidase (HRP)-conjugated goat anti-mouse secondary antibodies (1:2000, Bioworld, Shenzen, China) in blocking buffer at $37^{\circ} \mathrm{C}$ for $2 \mathrm{~h}$. The membranes were washed thoroughly with TBS-T before imaging using BIORAD UNIVERSAL HOOD II and Pierce ${ }^{\mathrm{TM}}$ ECL Western Blotting Substrate, according to the manufacturer's instructions.

\section{Cell viability assay using Cell Counting Kit-8}

The CYP4H31 ORF (GenBank: KM056314.1) of $C x$. pipiens pallens was amplified, inserted into vector $\mathrm{pIB} /$ V5-His, and transfected into C6/36 cells. Total RNA and protein were extracted from $\mathrm{C} 6 / 36$ cells of blank group (WT), the $\mathrm{pIB} / \mathrm{V} 5$-His control group (NC), and the experimental group (pIB/V5-His-CYP4H31). CYP4H31 overexpression in relation to deltamethrin resistance was assessed by measuring cell viability using Cell Counting Kit-8 (CCK-8; Dojindo, Japan) [28]. Cells (100 $\mu$ l) were added to each well of a 96-well plate $5 \times 10^{3}$ cells/well and incubated in a $5 \% \mathrm{CO}_{2}$-humidified incubator at $28^{\circ} \mathrm{C}$ for $24 \mathrm{~h}$. Then, the cells were treated with various concentrations of deltamethrin in $100 \mu \mathrm{l}\left(0,10^{0.5}, 10^{1}, 10^{1.5}, 10^{2}\right.$, and $10^{2.5} \mathrm{mg} / \mathrm{l}$ ) [29]. Twenty-four hours later, CCK-8 solution $(10 \mu \mathrm{l})$ was added to the wells and incubated for $28^{\circ} \mathrm{C}$ for $3 \mathrm{~h}$. The absorbance was then detected using dual wavelength spectrophotometry at $450 \mathrm{~nm}$ and $630 \mathrm{~nm}$ in a microplate reader. Dimethyl sulfoxide (DMSO, Sigma, St, Louis, MO, USA) was used to dissolve deltamethrin and the final concentration of DMSO was $0.5 \%(\mathrm{v} / \mathrm{v})$ for the different concentrations of deltamethrin [22]. Three biological replicates with three technical replicates were performed.

\section{American CDC bottle bioassay}

According to published guidelines, American Centers for Disease Control and Prevention (CDC) bottle bioassays were conducted to detect the sensitivity of mosquitoes injected with the miR-4448 mimic and si-CYP4H31 to deltamethrin [30]. Each 250-ml bottle and its cap were coated with $1 \mathrm{ml}$ of deltamethrin solution using inversion and rolling of the bottles. Control bottles were coated using $1 \mathrm{ml}$ of acetone. A sheet was used to cover all bottles, which were left to dry in the dark. Twenty

Table 2 List of the miR-4448 mimic, miRNA control mimic (NC1), si-CYP4H31, and control siRNA (NC2) sequences used for RNAi in Culex pipiens pallens

\begin{tabular}{lll}
\hline Name & Sense $\left(5^{\prime}-3^{\prime}\right)$ & Antisense $\left(5^{\prime}-3^{\prime}\right)$ \\
\hline miR-4448 & GGCUCGAUGGUCUAGGGGUAUG & UACCCCUAGACCAUCGAGCCUU \\
miRNA control mimic (NC1) & UUCUCCGAACGUGUCACGUTT & ACGUGACACGUUCGGAGAATT \\
si-CYP4H31 & GGGCAAAGAUUCGACAAAUTT & AUUUGUCGAAUCUUUGCCCTT \\
Control siRNA (NC2) & UUCUCCGAACGUGUCACGUTT & ACGUGACACGUUCGGAGAATT \\
\hline
\end{tabular}



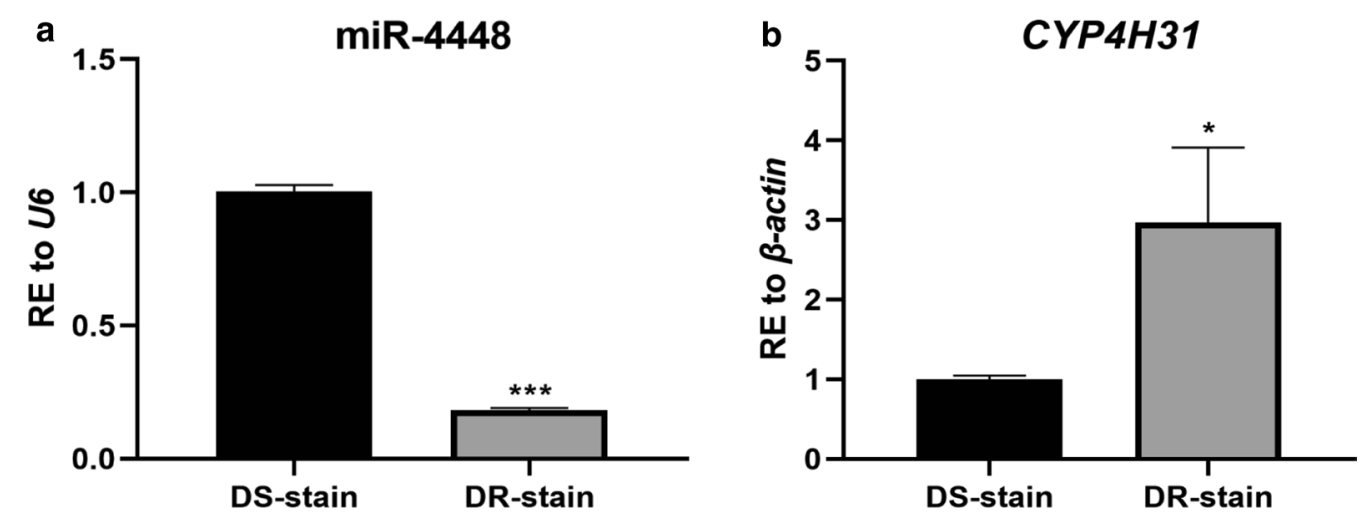

Fig. 1 Detecting the expression level of miR-4448 and CYP4H31 in mosquitoes using qRT-PCR. The expression of miR-4448 was lower and that of CYP4H31 was higher in the DR strain than that in the DS strain. a The expression of miR-4448 was 6.49-fold higher in the DS strain than in the DR strain. $\mathbf{b}$ The expression of CYP4H31 was 2.77-fold higher in the DR strain than in the DS strain. Data are representative of three technical replicates of three biological replicates and are indicated as the mean $\pm S E ;{ }^{*} P<0.05$, ${ }^{* * *} P<0.001$. RE relative expression, $q R T-P C R$ quantitative real-time reverse transcription PCR, DR-strain deltamethrin-resistant strain, DS-strain deltamethrin-susceptible strain

mosquitoes were placed in each bottle and exposed to deltamethrin or acetone for $120 \mathrm{~min}$. Following exposure, mosquitoes subjected to CYP4H31 knockdown were monitored at 15-min intervals up to $2 \mathrm{~h}$. Mosquitoes were considered dead if they could no longer stand [31]. The percent mortality ( $y$-axis) was plotted against time $(x$-axis) using a linear scale.

\section{Statistical analyses}

Statistically significant qualitative variables were detected using the GraphPad Prism 8.0 software (GraphPad Inc., La Jolla, CA, USA), and statistical significance was accepted at $P<0.05$. Qualitative variables were analyzed using the Chi-square test, while quantitative variables were assessed using analysis of variance [32, 33].

\section{Results}

\section{MiR-4448 targets CYP4H31}

Preliminary Solexa sequencing results showed that the expression of miR-4448 was significantly different between the DS and DR strains [22]. In this study, miR4448 showed 6.49-fold higher expression in the DS strain compared with that in the DR strain (Fig. 1a, ${ }^{* * * *} P<0.001$ ), while the predicted target gene, CYP4H31, showed 2.77fold lower expression in the DS strain than that in the DR strain (Fig. $1 \mathrm{~b},{ }^{*} P<0.05$ ). The contrasting expression patterns suggested that CYP4H31 might be the target gene of miR-4448. Dual-luciferase report assays were then used to determine the interaction between miR-4448 and CYP4H31 in vitro. Plasmids inserted with the $3^{\prime}$ UTRWT or $3^{\prime}$ UTR- $\triangle$ of CYP4H31 along with the control plasmid, pGL4.7, were cotransfected into HEK 293-T cells and then treated with the miRNA-4448 mimic or miRNA negative control (NC1). The results showed that miR-4448 treatment inhibited the luciferase activity from the WT $3^{\prime}$ UTR construct markedly (by 24.67\%), while no significant change occurred when the cells were treated with the negative control. Meanwhile, no increase in luciferase activity was observed in the $3^{\prime}$ UTR- $\Delta$ group when treated with the miR-4448 mimic (Fig. 2b, $\left.{ }^{*} P<0.01\right)$. Therefore, $C Y P 4 H 31$ was verified as a target of miR-4448 in vitro.

\section{MiR-4448 modulates mosquito deltamethrin resistance}

To determine whether miR-4448 could regulate deltamethrin resistance in mosquitoes, the miR-4448 mimic or miRNA mimic control was supplied to DR strain mosquitoes via oral feeding. The relative miR-4448 expression was 1.97 -fold higher in the mosquitoes fed with the miR-4448 mimic compared with those in the NC1 control group (Fig. 3a, ${ }^{* * *} P<0.001$ ), which suggested that in the DR strain, miR-4448 was successfully overexpressed. In these cells, the transcription level of CYP4H31 was decreased about $47.85 \%$ (Fig. $3 \mathrm{~b},{ }^{*} P<0.05$ ), which suggested that CYP4H31 is a direct in vivo target of miR4448. In the CDC bottle bioassay, the group fed with the miR-4448 mimic had a higher mortality rate compared with those in the NC1 groups. At 90 and $105 \mathrm{~min}$, the mortality rate of miR-4448 mimic-fed mosquitoes was $52.5 \%(21 / 40)$ and $65.0 \%$ (26/40), respectively, which was higher than those in the NC1 groups $(42.4 \%$ [14/33] and $51.5 \%$ [17/33]) (Fig. 3c, ${ }^{*} P<0.05$ ). To further validate the results obtained by oral feeding, we injected the miR4448 mimic or miRNA mimic control into each mosquito at $12 \mathrm{~h}$ PE. The microinjection results showed the efficient overexpression of miR-4448 (by 3.53 -fold) and the significantly decreased expression level of CYP4H31 $(65.82 \%)$ in the miR-4448 mimic injection group (Fig. 4a, 

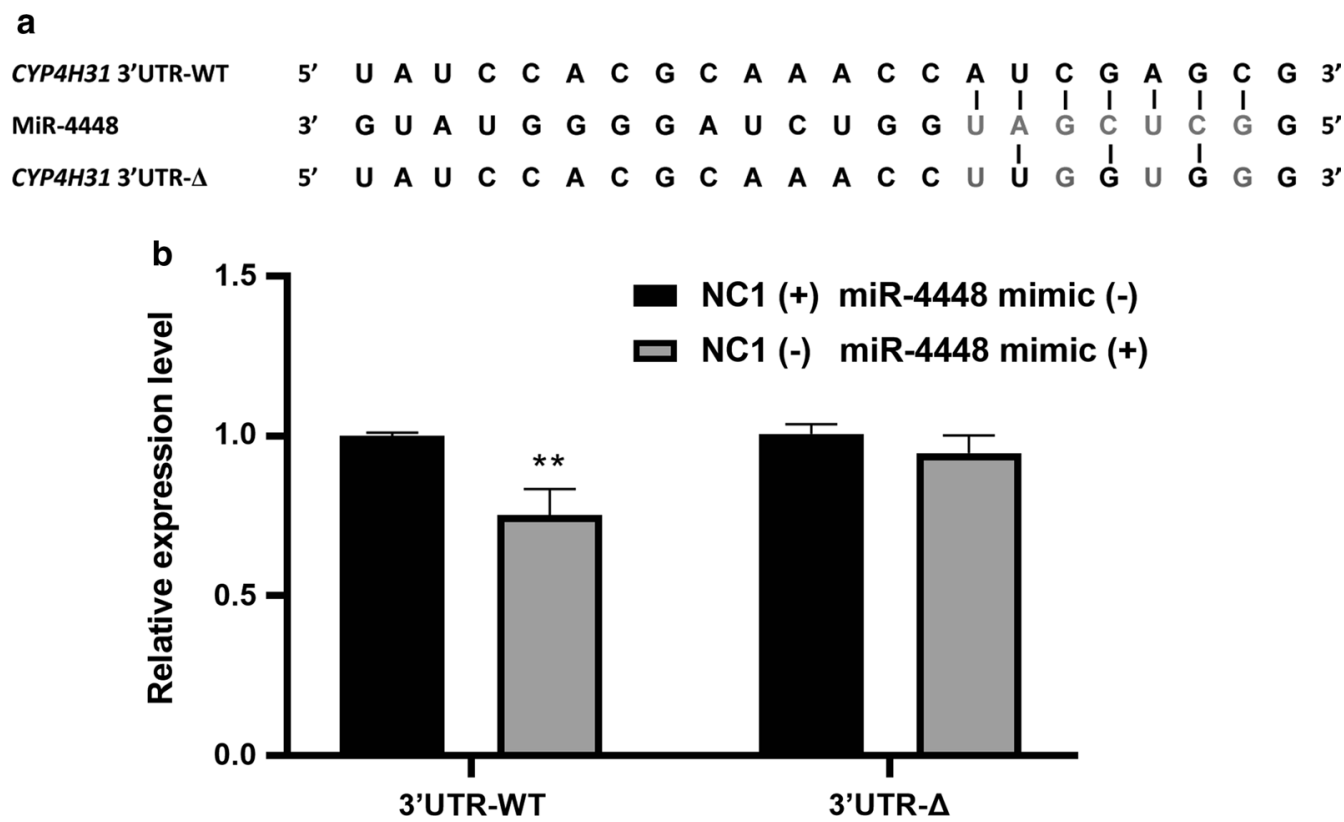

Fig. 2 Dual-luciferase report assays were used to determine the interaction between miR-4448 and CYP4H31 in vitro. MiR-4448 directly regulated CYP4H31 expression through 3' UTR sites. a The predicted CYP4H31 3' UTR miR-4448 binding site. b CYP4H31 assessed using a dual-luciferase reporter assay. The luciferase intensity was reduced by $24.67 \%$. Data are representative of three technical replicates of three biological replicates and are indicated as the mean $\pm \mathrm{SE}$; ${ }^{* *} P<0.01$. RE relative expression, $3^{\prime}$ UTR $3^{\prime}$ untranslated region

b, $* * 0.001)$. The expression trend was consistent with the results of the oral feeding experiment. Additionally, the results of the CDC bottle bioassay showed significantly higher mortality rates after injecting miR4448 mimic compared with the control. At $105 \mathrm{~min}$, in the mimic group, the mortality rate was $67.4 \%(31 / 46)$; in the NC1 group, the mortality rate was $43.9 \%(18 / 41)$; in the WT group, the mortality rate was $40.0 \%(24 / 60)$. Furthermore, at $120 \mathrm{~min}$, in the mimic group, the mortality rate was $78.3 \%(36 / 46)$, while it was $48.8 \%(20 / 41)$ in the NC1 group and $46.7 \%(28 / 60)$ in the WT group (Fig. 4c, $\left.{ }^{* *} P<0.01,{ }^{*} P<0.05\right)$. Taken together, oral feeding and microinjection both demonstrated that miR-4448 could modulate deltamethrin resistance of mosquitoes by downregulating the expression of CYP4H31.

\section{CYP4H31 functions in mosquito deltamethrin resistance}

To determine the function of CYP4H31 in mosquito deltamethrin resistance, transient transfection assays were performed in C6/36 cells in vitro, and their sensitivity to deltamethrin was determined after transfection. The results showed the expression level of CYP4H31 was 851.0-fold higher in the experimental group than in the NC group (Fig. $5 \mathrm{a},{ }^{* *} P<0.01$ ). Western blotting demonstrated that the band could be detected using antiHis-tag antibodies in the pIB/V5-His-CYP4H31 group (Fig. 5b). Thus, transcript and protein level detection proved the transfection was successful. To investigative the sensitivity of the transiently transfected C6/36 cells to deltamethrin, a CCK-8 kit was employed to detect cell viability after deltamethrin treatment. The percentage of viable cells among those transfected with pIB/V5-HisCYP4H31 was significantly higher than those in the NC and WT groups (Fig. 5 c, ${ }^{* * *} P<0.001$, ${ }^{* *} P<0.01,{ }^{*} P<0.05$ ). The data showed that $C Y P 4 H 31$ could increase mosquito cell resistance to deltamethrin.

To further evaluate whether CYP4H31 participates in mosquito resistance to deltamethrin in vivo, we conducted phenotypic experiments using CYP4H31 RNAi knockdown (si-CYP4H31) in DR strain mosquitoes. We expected that the RNAi-mediated ablation of the physiologically relevant target of miR-4448 would display the same phenotype as that caused by miR-4448 overexpression. CYP4H31 expression decreased by $41.90 \%$ in the si-CYP4H31 injection group compared with that in the negative control group (NC2) (Fig. 6a, ${ }^{* *} P<0.01$ ). RNAi silencing of CYP4H31 in mosquitoes resulted in increased sensitivity to deltamethrin. At $120 \mathrm{~min}$, the mortality rate was $74.3 \%(29 / 39)$ in si-CYP4H31-injected mosquitoes, while it was $46.7 \%(21 / 45)$ in the NC2 group and $48.7 \%(20 / 41)$ in the WT group (Fig. $6 \mathrm{~b},{ }^{* *} P<0.01$ ). These results suggested that $C Y P 4 H 31$ does indeed play a role in mosquito deltamethrin resistance. 

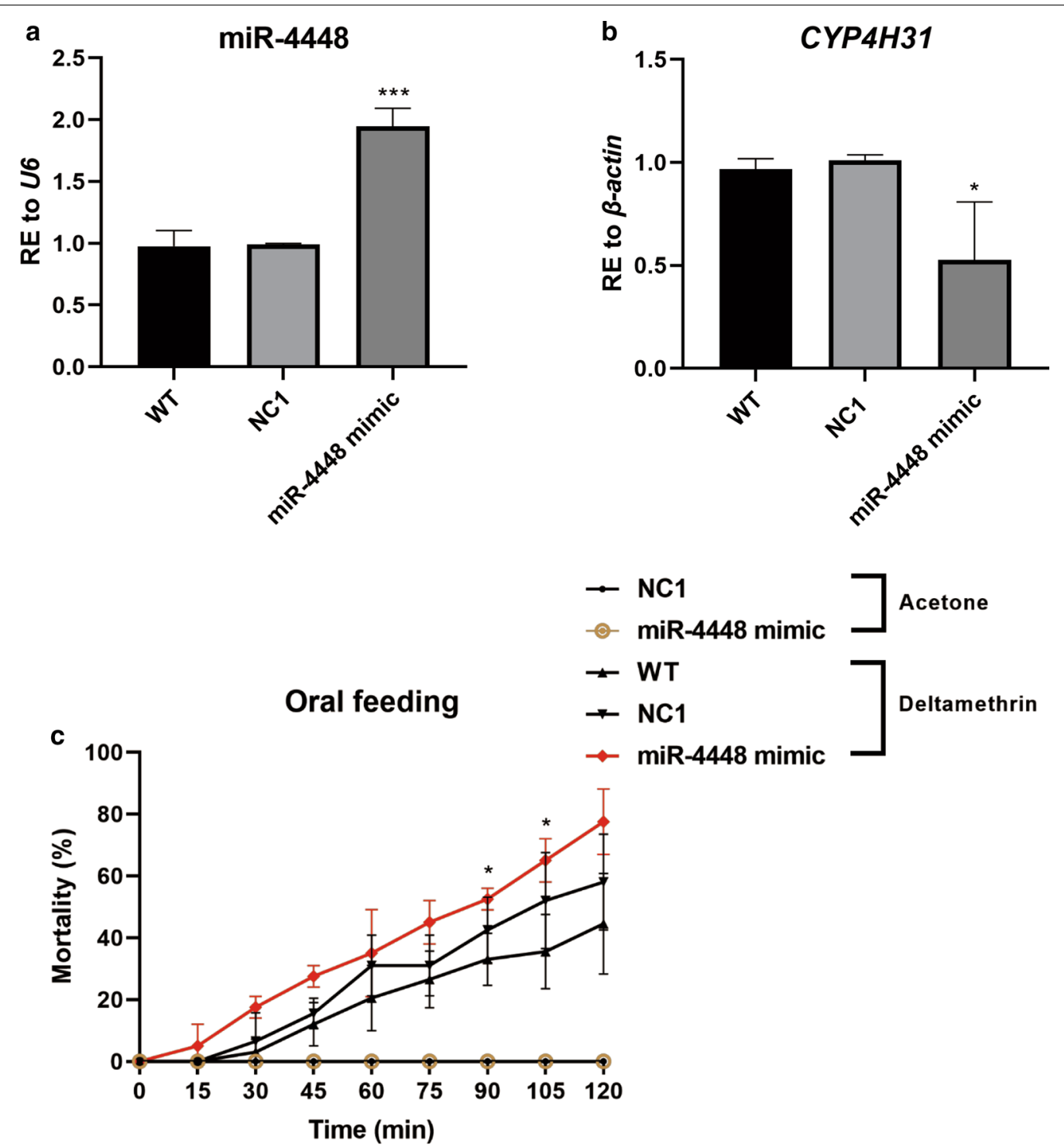

Fig. 3 CDC bottle assays were used to detect the function of miR-4448 by oral feeding of the miR-4448 mimic in DR strain mosquitoes. Oral feeding with the miR-4448 mimic could reduce mosquito resistance to deltamethrin. $\mathbf{a}$, $\mathbf{b}$ Oral feeding of the miR-4448 mimic upregulated the expression of miR-4448 (by 1.97-fold) and downregulated the expression of CYP4H31 (47.85\%) in DR strain. c Mosquito mortality was assessed after incubation for a $2 \mathrm{~h}$ in a CDC bottle containing $7 \mathrm{mg} / \mathrm{l}$ deltamethrin. The mortality of the miR-4448 mimic group was higher than that of the acetone control, WT, and miRNA control mimic (NC1) groups. At 90 and 105 min, the mortality rates of miR-4448 mimic-fed mosquitoes were 52.5\% $(21 / 40)$ and $65.0 \%$ (26/40), respectively, which were higher than those of the NC1 group (42.4\% [14/33] and 51.5\% [17/33]). Data are representative of three technical replicates of three biological replicates and are indicated as the mean $\pm S E ;{ }^{* * *} P<0.001,{ }^{*} P<0.05$. $R E$ relative expression, $D R$-strain deltamethrin-resistant strain

\section{Discussion}

Our results showed downregulation of miR-4448 in the DR strain, which suggested that miR-4448 might be involved in the regulation of deltamethrin resistance in Cx. pipiens pallens. Multiple approaches to miRNA target prediction were used to identify the physiologically relevant miR-4448 target contributing to the miR4448-mimic phenotypes. We identified CYP4H31 as a direct target of miR-4448 in vitro and in vivo. The results from bioinformatic predictions showed that miR4448 might directly regulate the expression of the P450 gene, CYP4H31. A dual-luciferase reporter assay using a luciferase reporter vector containing $C x$. pipiens pallens CYP4H31 3' UTR cotransfected with the miR-4448 mimic resulted in a decrease in Renilla luciferase activity in vitro. Overexpression of miR-4448 by oral feeding and 

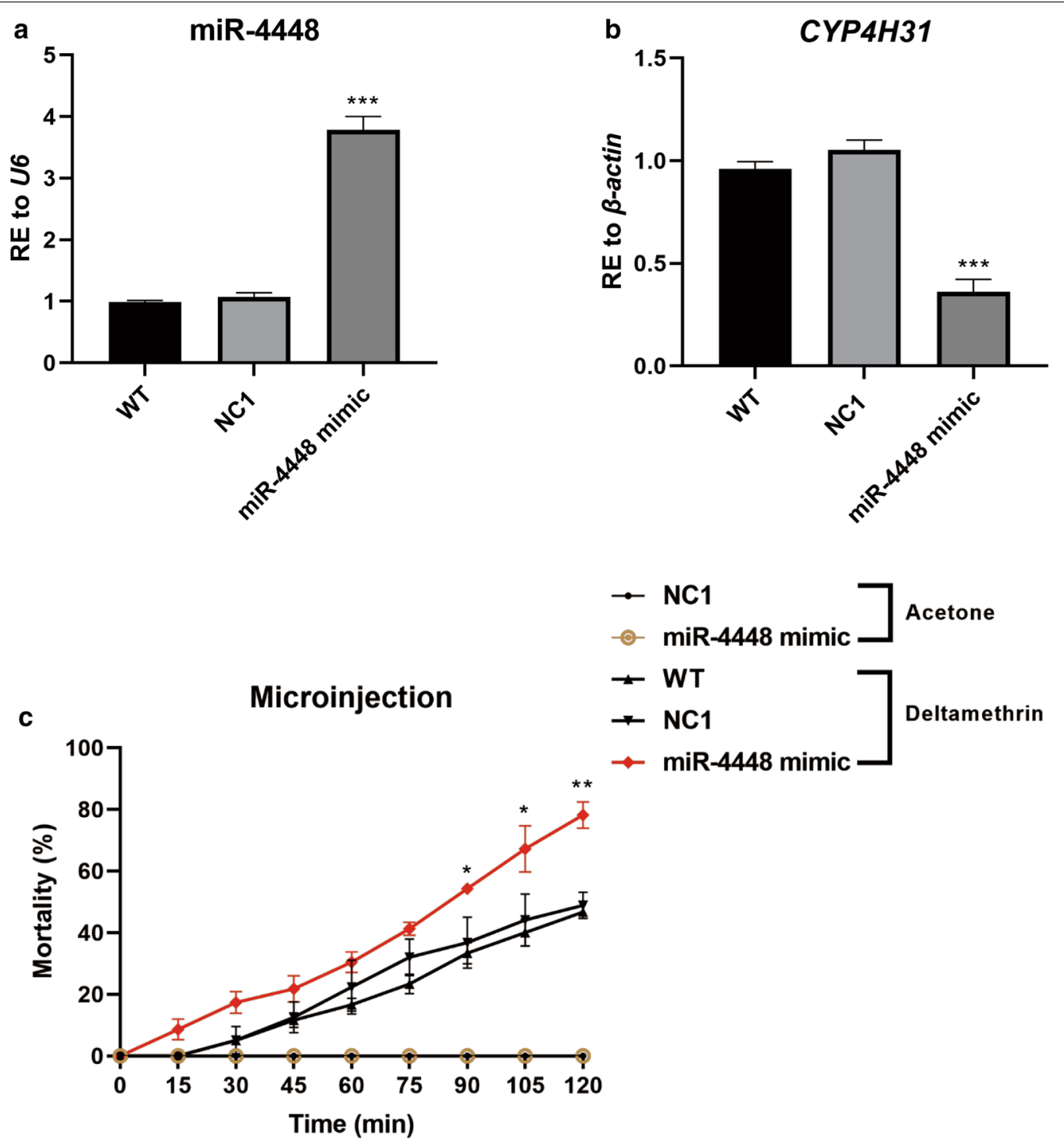

Fig. 4 CDC bottle assays were was used to detect the function of miR-4448 by microinjection of the miR-4448 mimic in DR strain mosquitoes. Microinjection of miR-4448 mimic could reduce mosquito resistance to deltamethrin. $\mathbf{a}$, b Microinjection of the miR-4448 mimic upregulated the expression of miR-4448 (by 3.53-fold) and downregulated the expression of CYP4H31 (65.82\%) in the DR strain. c Mosquito mortality was assessed after incubation for a $2 \mathrm{~h}$ in a CDC bottle containing $7 \mathrm{mg} / \mathrm{l}$ deltamethrin. The mortality of the miR- 4448 mimic group was higher than that of the acetone control, WT, and miRNA control mimic (NC1) groups. At $105 \mathrm{~min}$, in the mimic group, the mortality rate was 67.4\% (31/46); in the NC1 group, the mortality rate was 43.9\% (18/41); in the WT group, the mortality rate was 40.0\% (24/60). At 120 min, in the mimic group, the mortality rate was $78.3 \%$ (36/46), while it was $48.8 \%(20 / 41)$ in the NC1 group and $46.7 \%(28 / 60)$ in the WT group. Data are representative of three technical replicates of three biological replicates and are indicated as the mean $\pm \mathrm{SE}$; ${ }^{* *} P<0.001,{ }^{* *} P<0.01,{ }^{*} P<0.05$. RE relative expression, DR-strain deltamethrin-resistant strain

microinjection of an miR-4448 mimic reduced CYP4H31 expression and increased the mosquitoes' sensitivity to deltamethrin in vivo. By contrast, CYP4H31 overexpression decreased mosquito cell sensitivity to deltamethrin, and intrathoracic microinjection of dsRNA of CYP4H31 (si-CYP4H31) increased the mosquitoes' sensitivity to deltamethrin. Taken together, these results further confirmed CYP4H31 as an authentic miR-4448 target and indicated that miR-4448 might participate in deltamethrin-resistance by regulating CYP4H31 in mosquitoes.

MicroRNAs $(\sim 23 \mathrm{nt})$ are endogenous RNAs that play an important gene-regulatory role by pairing with the $3^{\prime}$ UTR of protein-coding gene mRNAs to direct their posttranscriptional repression [34]. Dysregulation of miRNAs has been reported in host-pathogen interactions, metabolism, development, and insecticide 

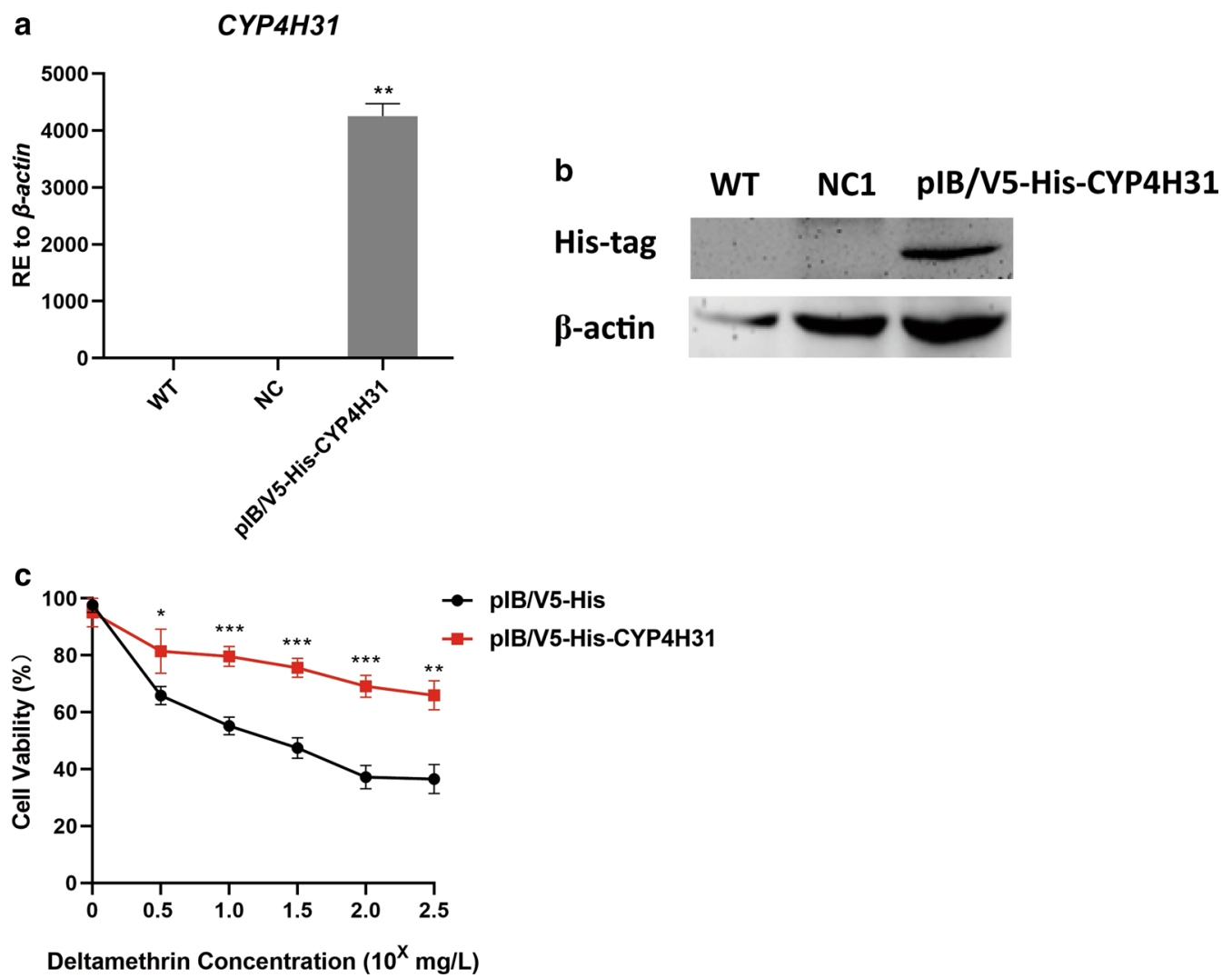

Fig. 5 CCK-8 assays were employed to detect cell viability after deltamethrin treatment. Overexpression of CYP4H31 upregulated the cell viability of C6/36 cells under deltamethrin stress. a qRT-PCR analysis of CYP4H31 in transfected C6/36 cells. The cells transfected with pIBN55-His-CYP4H31 showed a significantly higher transcription level (851.0-fold). b Western blotting experiments using His-tag antibodies to detect the CYP4H31 protein. c The plB/N5-His-CYP4H31 construct-transfected C6/36 cells were treated with deltamethrin and their viability was calculated using a CCK-8 kit. The viability of pIB/V5-His-CYP4H31-transfected cells was higher than that in the plB/N5-His group. Data are representative of three technical replicates of three biological replicates and are indicated as the mean $\pm \mathrm{SE}$; ${ }^{* * *} P<0.001,{ }^{* *} P<0.01,{ }^{*} P<0.05$. RE relative expression

resistance [21]. Previously, our group performed Solexa high-throughput sequencing and showed that miR-4448 was highly expressed in DS strain mosquitoes [22]. In this study, to further investigate the function of miR-4448 in deltamethrin-resistant mosquitoes, we first identified that the pre-miR-4448 sequence was present in Cx. pipiens pallens. The qRT-PCR results showed that the conserved miRNA, miR-4448, was enriched in the DS strain mosquitoes.

Many studies have shown that multiple, complex resistance mechanisms, particularly increased metabolic detoxification of insecticides, are likely to be responsible for insecticide resistance (reviewed in [16]). Commonly, metabolic detoxification, especially by CYPs, is the main molecular mechanism of insecticide resistance [35]. The overproduction of CYPs in resistant populations could, in principle, lead to a negative cross-resistance between different insecticides in insects, in which detoxification of one insecticide (for example pyrethroids) occurs at the same time as activation of another pro-insecticide (such as organophosphates, ketoenols, or clorfenapyr) [36]. Recently, researchers reported that miRNAs could mediate insecticide resistance through CYP genes [37-39]. In the present study, CYP4H31 was identified as a direct in vitro and in vivo target of miR-4448. A dual-luciferase reporter assay comprising a CYP4H31 3' UTR-containing luciferase reporter vector, which was cotransfected together with the miR-4448 mimic, produced decreased in vitro Renilla luciferase activity. Meanwhile, microinjection of the miR-4448 mimic decreased the CYP4H31 transcript level in vivo, which further confirmed that in mosquitoes, CYP4H31 is a target gene of miR-4448. CYP4H31 belongs to the CYP4 family as a member of the monooxygenase cytochrome P450 (CYPs) superfamily [40]. CYP4 family genes were proposed as the most important $P 450$ genes involved in pyrethroid resistance in Anopheles sinensis [41].

Next, using oral feeding and RNAi technology, in combination with the $\mathrm{CDC}$ bottle assay, the present study made significant progress toward determining the 
a

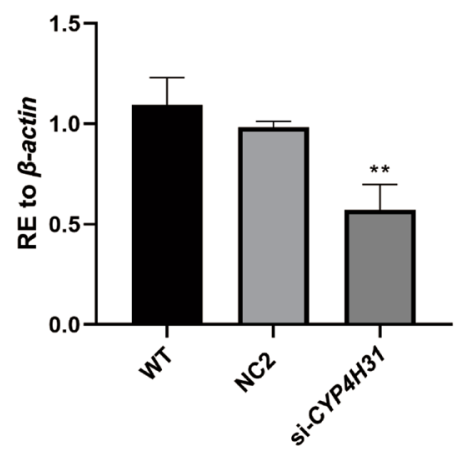

b

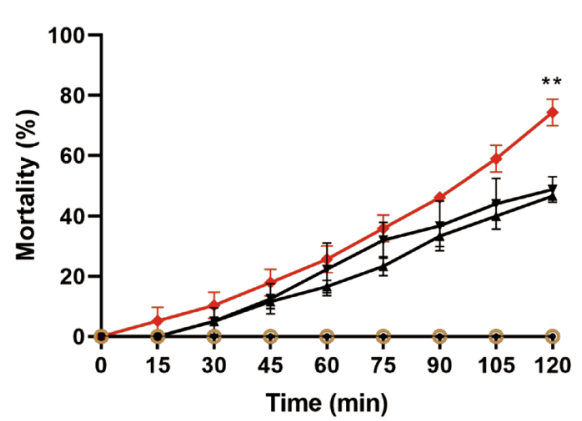

$\rightarrow$ NC2 $\rightarrow$ si-CYP4H31 $]$ Acetone

- WT

$\rightarrow \mathrm{NC2}$ Deltamethrin

Fig. 6 CYP4H31 RNAi (Si-CYP4H31) in DR strain mosquitoes. Microinjection of an siRNA targeting CYP4H31 in female adult mosquitoes reduced their resistance to deltamethrin. a Microinjection of si-CYP4H31 downregulated the expression of CYP4H31 (41.90\%) in the DR stain. b Mosquito mortality was assessed after incubation for a $2 \mathrm{~h}$ in a CDC bottle containing $7 \mathrm{mg} / \mathrm{l}$ deltamethrin. The mortality of the si-CYP4H31 group was higher than that in the acetone control, WT, and control siRNA (NC2) groups. At 120 min, the mortality rate was 74.3\% (29/39) in si-CYP4H31-injected mosquitoes, while it was $46.7 \%(21 / 45)$ in the NC2 group and $48.7 \%$ (20/41) in the WT group. Data are representative of three technical replicates of three biological replicates and are indicated as the mean $\pm \mathrm{SE}$; ${ }^{* *} P<0.01$. RE relative expression, $D R$-strain deltamethrin-resistant strain

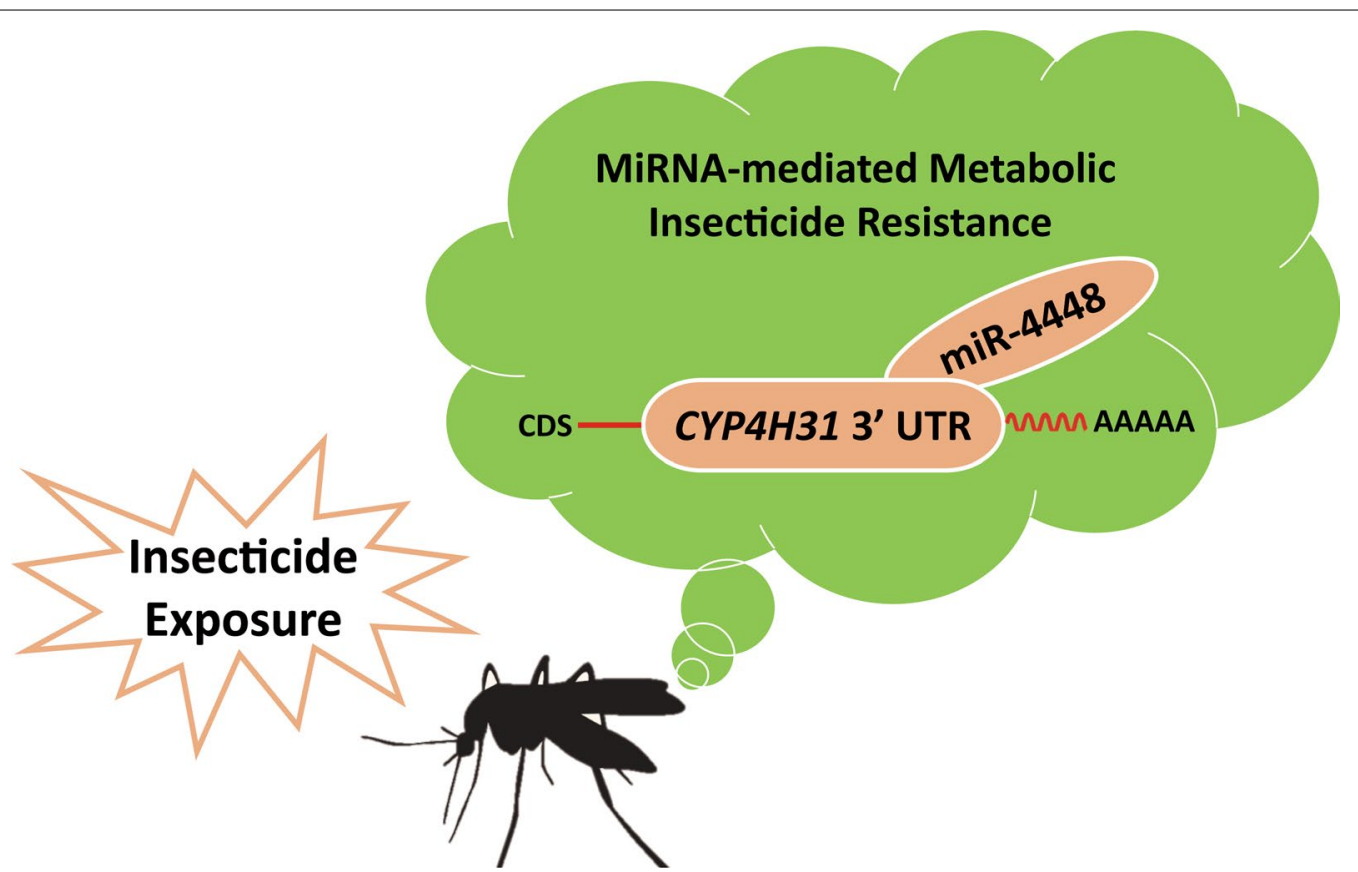

Fig. 7 The regulatory map of miR-4448's involvement in deltamethrin resistance by targeting CYP4H31 in Culex pipiens pallens

regulatory role of miRNAs in insecticide resistance. In mosquitoes, miR-4448 function decreases deltamethrin resistance by inhibiting $C Y P 4 H 31$ expression. However, the mortality of miR-4448-mimic-supplied mosquitoes showed no significant change compared with the controls, possibly because we could not control the amount of microRNA mimic taken up by each mosquito. To date, novel strategies, including transgenic plants, engineered microorganisms, and nano-scale formulations, have been developed to improve the efficacy of miRNA; however, many hurdles must be overcome before this technology becomes a reliable method of pest management [42]. Notwithstanding, in our study, the miR-4448mimic-injected mosquitoes displayed drastically higher 
sensitivity to deltamethrin and resulted in significantly increased mortality in the DR strain. Furthermore, our study showed that high expression of CYP4H31 could increase resistance to deltamethrin and consequently improve cell viability. In contrast, low expression of CYP4H31 after miR-4448 mimic oral feeding or microinjection, and CYP4H31 RNAi, resulted in increased sensitivity to deltamethrin and higher mortality. Taken together, our findings demonstrated that CYP4H31 is related to mosquito deltamethrin resistance.

\section{Conclusion}

Our study has established a fundamental role for miR4448 in the regulation of mosquito deltamethrin resistance through its target, CYP4H31, in mosquitoes (Fig. 7). Further investigation of CYP4H31, e.g. using gene editing, is warranted to determine its exact function in deltamethrin resistance. Our findings revealed a mechanism of insecticide resistance, which could lead to new methods to control mosquito populations.

\begin{abstract}
Abbreviations
miRNA: MicroRNA; DR strain: Deltamethrin-resistant strain; DS strain: Deltamethrin-susceptible strain; qRT-PCR: Quantitative real-time reverse transcription PCR; gDNA: Genomic DNA; 3'-UTR: 3' Untranslated region; 3 d PE: 3 days posteclosion; CCK-8: Cell Counting Kit-8.
\end{abstract}

\section{Acknowledgements}

We are grateful to Prof. Maoqing Gong of Ji Nan University for their kind help and donation of Culex pipiens pallens mosquitoes. A team of workers from Ji Nan University $\left(\mathrm{E} 117^{\circ}, \mathrm{N} 36^{\circ} 38^{\prime}\right)$ sampled the Culex pipiens pallens mosquitoes from Tangkou town, Ji Nan city, Shandong province.

\section{Authors' contributions}

$X X L, S L H, H T Y$, and HBZ performed the experiments. XXL and SLH wrote the manuscript and prepared the figures. YS, DZ, LM, BS, and CLZ conceived the idea and coordinated the project. All authors read and approved the final manuscript.

\section{Funding}

This work was funded by the National Natural Science Foundation of China (grant nos. 81672058, 81672056, 81772227, and 81971970) and the National S and T Major Program (grant no. 2017ZX10303404-002-006). The funding bodies had no role in the design of the study and the collection, analysis, and interpretation of data and in writing the manuscript.

\section{Availability of data and materials}

Data supporting the conclusions of this article are included within the article. All data are fully available without restriction upon request.

\section{Declarations}

\section{Ethics approval and consent to participate}

All animal procedures were approved by the Institutional Animal Care and Use Committee (IACUC) of Nanjing Medical University for the use of laboratory animals (no. IACUC-1812047).

\section{Consent for publication}

Not applicable.

\section{Competing interests}

The authors declare that they have no competing interests.
Received: 7 December 2020 Accepted: 26 February 2021

Published online: 16 March 2021

\section{References}

1. Samuel GH, Adelman ZN, Myles KM. Antiviral immunity and virusmediated antagonism in disease vector mosquitoes. Trends Microbiol. 2018:26(5):447-61

2. Lee H, Halverson S, Ezinwa N. Mosquito-borne diseases. Prim Care. 2018:45(3):393-407.

3. Dahmana $\mathrm{H}$, Mediannikov O. Mosquito-borne diseases emergence/ resurgence and how to effectively control it biologically. Pathogens. 2020;9(4):310.

4. Chang X, Zhong D, Fang Q, Hartsel J, Zhou G, Shi L, Fang F, Zhu C, Yan G. Multiple resistances and complex mechanisms of Anopheles sinensis mosquito: a major obstacle to mosquito-borne diseases control and elimination in China. PLoS Negl Trop Dis. 2014;8(5):e2889.

5. Semenza JC, Suk JE. Vector-borne diseases and climate change: a European perspective. FEMS Microbiol Lett. 2018:365(2)

6. Govindarajan M, Benelli G. Eco-friendly larvicides from Indian plants: effectiveness of lavandulyl acetate and bicyclogermacrene on malaria, dengue and Japanese encephalitis mosquito vectors. Ecotox Environ Safe. 2016:133:395-402.

7. Scott JG, Yoshimizu MH, Kasai S. Pyrethroid resistance in Culex pipiens mosquitoes. Pestic Biochem Physiol. 2015;120:68-76.

8. Shaw WR, Catteruccia F. Vector biology meets disease control: using basic research to fight vector-borne diseases. Nat Microbiol. 2019:4(1):20-34.

9. Chrustek A, Holynska-Iwan I, Dziembowska I, Bogusiewicz J, Wroblewski M, Cwynar A, Olszewska-Slonina D. Current Research on the safety of pyrethroids used as insecticides. Medicina. 2018;54(4):61.

10. Xu L, Wu M, Han Z. Overexpression of multiple detoxification genes in deltamethrin resistant Laodelphax striatellus (Hemiptera: Delphacidae) in China. PLoS ONE. 2013;8(11):e79443.

11. Moyes CL, Vontas J, Martins AJ, Ng LC, Koou SY, Dusfour I, Raghavendra K, Pinto J, Corbel V, David JP, et al. Contemporary status of insecticide resistance in the major Aedes vectors of arboviruses infecting humans. PLoS Negl Trop Dis. 2017;11(7):e0005625

12. Marcombe S, Fustec B, Cattel J, Chonephetsarath S, Thammavong P, Phommavanh N, David JP, Corbel V, Sutherland IW, Hertz JC, et al. Distribution of insecticide resistance and mechanisms involved in the arbovirus vector Aedes aegypti in Laos and implication for vector control. PLoS Negl Trop Dis. 2019;13(12):e0007852.

13. Stica C, Jeffries CL, Irish SR, Barry Y, Camara D, Yansane I, Kristan M, Walker T, Messenger LA. Characterizing the molecular and metabolic mechanisms of insecticide resistance in Anopheles gambiae in Faranah, Guinea. Malar J. 2019;18(1):244.

14. Itokawa K, Komagata O, Kasai S, Ogawa K, Tomita T. Testing the causality between CYP9M10 and pyrethroid resistance using the TALEN and CRISPR/ Cas9 technologies. Sci Rep. 2016;6:24652.

15. Riveron JM, Ibrahim SS, Chanda E, Mzilahowa T, Cuamba N, Irving H, Barnes KG, Ndula M, Wondji CS. The highly polymorphic CYP6M7 cytochrome P450 gene partners with the directionally selected CYP6P9a and CYP6P9b genes to expand the pyrethroid resistance front in the malaria vector Anopheles funestus in Africa. BMC Genomics. 2014;15:817.

16. Liu N. Insecticide resistance in mosquitoes: impact, mechanisms, and research directions. Annu Rev Entomol. 2015;60:537-59.

17. Gong Y, LiT, Zhang L, Gao X, Liu N. Permethrin induction of multiple cytochrome P450 genes in insecticide resistant mosquitoes, Culex quinquefasciatus. Int J Biol Sci. 2013;9(9):863-71.

18. Matsuyama H, Suzuki HI. Systems and synthetic microRNA biology: from biogenesis to disease pathogenesis. Intern J Mol Sci. 2019;21(1):132.

19. Agarwal V, Bell GW, Nam JW, Bartel DP. Predicting effective microRNA target sites in mammalian mRNAs. elife 2015:4.

20. Saliminejad K, Khorram Khorshid HR, Soleymani Fard S, Ghaffari SH. An overview of microRNAs: biology, functions, therapeutics, and analysis methods. J Cell Physiol. 2019;234(5):5451-65.

21. Feng $X$, Zhou S, Wang J, Hu W. microRNA profiles and functions in mosquitoes. PLoS Negl Trop Dis. 2018;12(5):e0006463.

22. Hong S, Guo Q, Wang W, Hu S, Fang F, Lv Y, Yu J, Zou F, Lei Z, Ma K, et al. Identification of differentially expressed microRNAs in Culex pipiens and 
their potential roles in pyrethroid resistance. Insect Biochem Mol Biol. 2014;55:39-50.

23. <One Shot ${ }^{\circledR}$ TOP10 Competent Cells_man.pdf>.

24. Rehmsmeier M, Steffen P, Hochsmann M, Giegerich R. Fast and effective prediction of microRNA/target duplexes. RNA. 2004;10(10):1507-17.

25. Dedeoglu BG. High-throughput approaches for microRNA expression analysis. Methods Mol Biol. 2014:1 107:91-103.

26. Livak KJ, Schmittgen TD. Analysis of relative gene expression data using real-time quantitative PCR and the 2(-Delta Delta C(T)) method. Methods. 2001;25(4):402-8.

27. $\quad$ InsectSelect ${ }^{\mathrm{TM}}$ BSD System For Stable Expression of Heterologous Proteins in Lepidopteran Insect Cell Lines using plBV5-His_man.pdf>.

28. Yu J, Hu S, Ma K, Sun L, Hu H, Zou F, Guo Q, Lei Z, Zhou D, Sun Y, et al. Ribosomal protein $\$ 29$ regulates metabolic insecticide resistance through binding and degradation of CYP6N3. PLoS ONE. 2014;9(4):e94611.

29. Sun H, Sun L, He J, Shen B, Yu J, Chen C, Yang M, Sun Y, Zhang D, Ma L, et al. Cloning and characterization of ribosomal protein S29, a deltamethrin resistance associated gene from Culex pipiens pallens. Parasitol Res. 2011;109(6):1689-97.

30. Center for Global Health (U.S.). Division of Parasitic Diseases and Malaria.

31. <Guideline for Evaluating Insecticide Resistance in Vectors.pdf>.

32. Zou FF, Guo Q, Sun Y, Zhou D, Hu MX, Hu HX, Liu BQ, Tian MM, Liu XM, Li XX, et al. Identification of protease $\mathrm{m} 1$ zinc metalloprotease conferring resistance to deltamethrin by characterization of an AFLP marker in Culex pipiens pallens. Parasites Vectors. 2016;9:172.

33. Dagg K, Irish S, Wiegand RE, Shililu J, Yewhalaw D, Messenger LA. Evaluation of toxicity of clothianidin (neonicotinoid) and chlorfenapyr (pyrrole) insecticides and cross-resistance to other public health insecticides in Anopheles arabiensis from Ethiopia. Malar J. 2019;18(1):49.

34. Bartel DP. MicroRNAs: target recognition and regulatory functions. Cell. 2009:136(2):215-33

35. Smith LB, Sears C, Sun H, Mertz RW, Kasai S, Scott JG. CYP-mediated resistance and cross-resistance to pyrethroids and organophosphates in Aedes aegypti in the presence and absence of kdr. Pestic Biochem Physiol. 2019;160:119-26.
36. Vontas J, Katsavou E, Mavridis K. Cytochrome P450-based metabolic insecticide resistance in Anopheles and Aedes mosquito vectors: muddying the waters. Pestic Biochem Physiol. 2020;170:104666.

37. Tian M, Liu B, Hu H, Li X, Guo Q, Zou F, Liu X, Hu M, Guo J, Ma L, et al. MiR-285 targets P450 (CYP6N23) to regulate pyrethroid resistance in Culex pipiens pallens. Parasitol Res. 2016;115(12):4511-7.

38. Liu B, Tian M, Guo Q, Ma L, Zhou D, Shen B, Sun Y, Zhu C. MiR-932 regulates pyrethroid resistance in Culex pipiens pallens (Diptera: Culicidae). J Med Entomol. 2016:53(5):1205-10.

39. Guo Q, Huang Y, Zou F, Liu B, Tian M, Ye W, Guo J, Sun X, Zhou D, Sun Y, et al. The role of miR-2 approximately 13 approximately 71 cluster in resistance to deltamethrin in Culex pipiens pallens. Insect Biochem Mol Biol. 2017:84:15-22.

40. Traverso L, Lavore A, Sierra I, Palacio V, Martinez-Barnetche J, Latorre-Estivalis JM, Mougabure-Cueto G, Francini F, Lorenzo MG, Rodriguez MH, et al. Comparative and functional triatomine genomics reveals reductions and expansions in insecticide resistance-related gene families. PLoS NegI Trop Dis. 2017;11(2)::0005313.

41. Yan ZW, He ZB, Yan ZT, Si FL, Zhou Y, Chen B. Genome-wide and expressionprofiling analyses suggest the main cytochrome $\mathrm{P} 450$ genes related to pyrethroid resistance in the malaria vector, Anopheles sinensis (Diptera Culicidae). Pest Manag Sci. 2018;74(8):1810-20.

42. Kunte N, McGraw E, Bell S, Held D, Avila LA. Prospects, challenges and current status of RNAi through insect feeding. Pest Manag Sci. 2020;76(1):26-41.

\section{Publisher's Note}

Springer Nature remains neutral with regard to jurisdictional claims in published maps and institutional affiliations.
Ready to submit your research? Choose BMC and benefit from:

- fast, convenient online submission

- thorough peer review by experienced researchers in your field

- rapid publication on acceptance

- support for research data, including large and complex data types

- gold Open Access which fosters wider collaboration and increased citations

- maximum visibility for your research: over $100 \mathrm{M}$ website views per year

At $\mathrm{BMC}$, research is always in progress.

Learn more biomedcentral.com/submissions 